\title{
Wound healing - A literature review*
}

\author{
Ana Cristina de Oliveira Gonzalez ${ }^{1}$ \\ Zilton de Araújo Andrade ${ }^{1}$
}

\author{
Tila Fortuna Costa ${ }^{2}$ \\ Alena Ribeiro Alves Peixoto Medrado²
}

DOI: http://dx.doi.org/10.1590/abd1806-4841.20164741

\begin{abstract}
Regeneration and tissue repair processes consist of a sequence of molecular and cellular events which occur after the onset of a tissue lesion in order to restore the damaged tissue. The exsudative, proliferative, and extracellular matrix remodeling phases are sequential events that occur through the integration of dynamic processes involving soluble mediators, blood cells, and parenchymal cells. Exsudative phenomena that take place after injury contribute to the development of tissue edema. The proliferative stage seeks to reduce the area of tissue injury by contracting myofibroblasts and fibroplasia. At this stage, angiogenesis and reepithelialization processes can still be observed. Endothelial cells are able to differentiate into mesenchymal components, and this difference appears to be finely orchestrated by a set of signaling proteins that have been studied in the literature. This pathway is known as Hedgehog. The purpose of this review is to describe the various cellular and molecular aspects involved in the skin healing process.
\end{abstract}

Keywords: Cell proliferation; Hedgehog proteins; Inflammation; Wound Healing

Cutaneous wound healing is an essential physiological process consisting of the collaboration of many cell strains and their products. ${ }^{1}$ Attempts to restore the lesion induced by a local aggression begin very early on in the inflammatory stage. In the end, they result in repair, which consists of the substitution of specialized structures brought about by the deposition of collagen, and regeneration, which corresponds to the process of cell proliferation and posterior differentiation through preexisting cells in the tissue and/or stem cells. ${ }^{2}$ These mechanisms do not mutually exclude themselves, that is, after a skin lesion, in the same tissue, regeneration and repair can occur, depending on the cell strains compromised by the injury.

Tissue regeneration and repair processes occur after the onset of the lesion. Be that due to the trauma or resulting from a specific pathological condition. One lesion is created by all of the stimuli that break the physical continuity of functional tissues. The stimuli that cause lesions can be external or internal, as well as physical, chemical, electric, or thermal. Moreover, the lesions can result in damage to specific organelles or to cells as a whole. ${ }^{1}$

Tissue repair is a simple linear process in which the growth factors cause cell proliferation, thus leading to an integration of dynamic changes that involve soluble mediators, blood cells, the production of the extracellular matrix, and the proliferation of parenchymal cells. The skin healing process, according to Mitchel et al., illustrates the principles of repair for the majority of tissues. ${ }^{3}$

Cell and biochemical events in wound repair can be divided into the following stages: inflammatory reaction, cell proliferation and synthesis of the elements which make up the extracellular matrix, and the posterior period, called remodeling. ${ }^{4}$ These stages are not mutually excluding, but rather overlap over time (Graph 1 ). ${ }^{3}$

This literature review aims to highlight the biological processes involved during wound healing, with emphasis on the cells, growth factors, and cytokines that participate in the tissue repair process.

\section{INFLAMMATORY STAGE}

In a vascular inflammatory response, the lesioned blood vessels contract and the leaked blood coagulates, contributing to the maintenance of its integrity. The coagulation consists of an aggregation of thrombocytes and platelets in a fibrin network, relying on the action of specific factors through the activation and aggregation of these cells. ${ }^{5}$ The fibrin network, in addition to reestablishing homeostasis and forming a barrier against the invasion of microorganisms, organizes the necessary temporary matrix for cell migration (Figure 1), which in turn restores the skin's function as a protective barrier, maintaining the skin's integrity. ${ }^{1}$ This also makes it possible for cell migration to the lesion's microenvironment and the stimulation of

Received on 22.05.2015

Approved by the Advisory Board and accepted for publication on 10.08.2015

* Work conducted at the Gonçalo Moniz Research Center - Fundação Oswaldo Cruz (CPqGM/Fiocruz), Salvador, BA, Brazil.

Financial Support: None.

Conflict of Interest: None.

Fundação Oswaldo Cruz (Fiocruz), Salvador, BA, Brazil.

Bahiana School of Medicine and Public Health (EBMSP), Salvador, BA, Brazil.

(C)2016 by Anais Brasileiros de Dermatologia 
fibroblast proliferation.

Cell response in the inflammatory stage is characterized by the influx of leukocytes in the wound area (Figure 2). Such a response is very quick and coincides with the key signs of inflammation, which are revealed by the edema and the erythema at the location of the lesion. Normally, cell response is established within the first 24 hours and can extend for up to two days. A quick activation of the immune cells in the tissue may also occur, as happens with mastocytes, gamma-delta cells, and Langerhans cells, which secrete chemokines and cytokines. Inflammation is a localized and protective tissue response that is unleashed by the lesion, causing tissue destruction. Inflammatory cells play an important role in wound healing and contribute to the release of lysosomal enzymes and reactive oxygen species, as well as facilitate the clean-up of various cell debris. ${ }^{6}$

Buckley argues that the interaction of leukocytes and stromal cells during an acute inflammatory response resolves around the inflammatory focus. ${ }^{7}$ Neutrophils are known for expressing many pro-inflammatory cytokines and a large quantity of highly active antimicrobial substances, such as reactive oxygen species (ROS), cationic peptides, and proteases at the location of the lesion. The inflammatory response continues with the active recruitment of the neutrophils in response to the activation of the complement system,

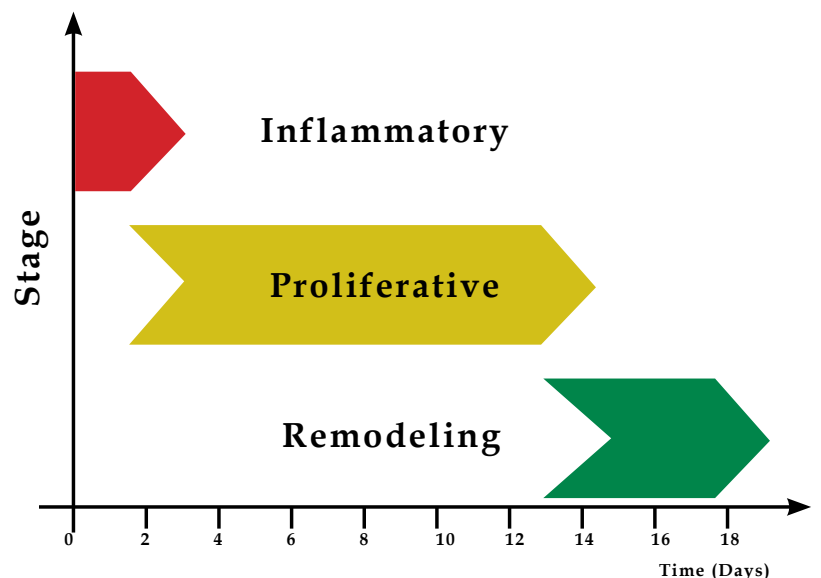

GrapH 1: Sequential illustration of the stages involved in tissue repair

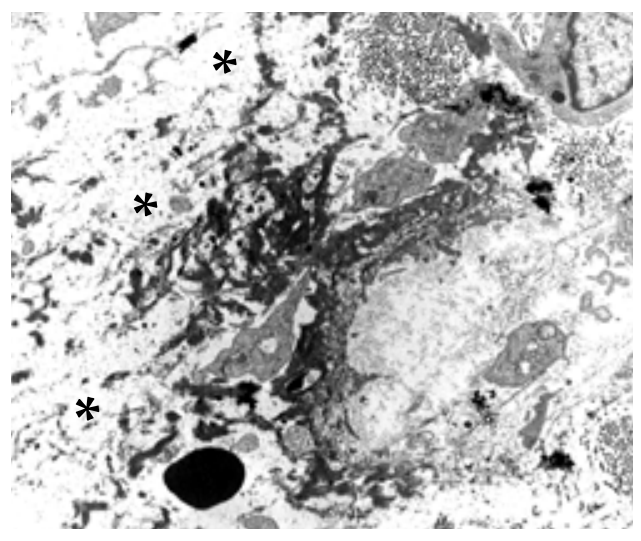

Figure 1:

A c cumulation of fibrin (asterisk) in the middle of the edema area in the extracellular matrix (Scanning Electron Microscopy $4,500 \mathrm{X})$ platelet degranulation, and bacterial degradation products. ${ }^{8}$ These are attracted by many inflammatory cytokines produced by activated platelets, endothelial cells, and degradation products of pathogenic agents. ${ }^{9}$ In this manner, the neutrophils are the primary activated and recruited cells that play a role in the clean-up of the tissue, as well as contribute to the death of invading agents. ${ }^{3}$

Only a few hours after the lesion, a quantity of neutrophils transmigrate through the endothelial cells present in the blood capillary walls, which are activated by pro-inflammatory cytokines, such as IL-1 $\beta$, TNF- $\alpha$ (tumor necrosis factor alpha), and IFN- $\gamma$ (interferon gamma) at the location of the lesion. Such cytokines promote the expression of many classes of adhesion molecules. These adhesion molecules are a determining factor for the diapedesis of neutrophils, including selectins and integrins - (CD11a/CD18 (LFA-1); CD11b/ CD18 (MAC-1); CD11c/CD18 (gp150, 95); CD11d/CD18)² - which interact with those already present on the membrane surface of endothelial cells. The referent cells also influence many other aspects of tissue repair, such as the resolution of fibrin and extracellular matrix coagulation, the prompting of angiogenesis, and reepithelialization. ${ }^{1}$

As of 48 hours after the onset of the lesion, the migration of monocytes from neighboring blood vessels, which also infiltrate the lesion area, is intensified, and, with the generation of the new genic expression profiles, are differentiated into macrophages. These, which are activated through chemokine signaling, can act as cells that present antigens and that aid neutrophils in phagocytosis. ${ }^{2}$

Thus, in addition to resident macrophages, the main population of macrophages in the lesion is recruited from the blood in response to chemotactic products, as can be seen in extracellular matrix protein fragments, TGF- $\beta, \mathrm{MCP}-1$ (protein 1 chemotactic for monocytes). ${ }^{10}$

Based on the profiles of genic expression, macrophages can be classified as classically activated (M1 pro-inflammatory) and alternatively activated (M2 anti-inflammatory and pro-angiogenic). ${ }^{11}$ These macrophages release growth factors, such as PDGF and VEGF, which are commonly necessary for the triggering and propagation of new tissue in the lesioned area, since animals with a depletion of macrophages present defects in wound repair, conferring upon these cells a key role in the transition of the exsudative stage to the proliferative stage within the tissue repair

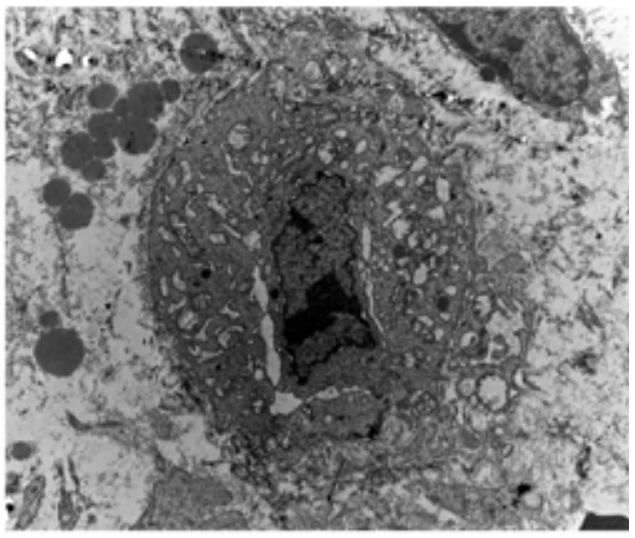

Figure 2:

Electromicrography of a leukocyte, with evident hydropic degeneration in the exsudative stage of the inflammatory process (Scanning Electron Microscopy $7,000 X)$ 
process. ${ }^{12}$

Macrophages perform the functions of muscular debris phagocytosis, as well as the production and release of cytokines and pro-angiogenic, inflammatory, and fibrogenic factors, and of free radicals. ${ }^{13}$ Moreover, the macrophages, upon secreting chemotactic factors, attract other inflammatory cells to the wound area. They also produce prostaglandins, which function as potent vasodilators, affecting the permeability of micro-blood vessels. Together, such factors cause the activation of endothelial cells. ${ }^{14}$ These cells, according to Mendonça \& Coutinho Netto, also produce PDGF, TGF beta, FGF, and VEGF, which stand out as the main cytokines capable of stimulating the formation of granulation tissue. ${ }^{15}$

\section{PROLIFERATIVE STAGE}

The aim of the proliferative stage is to diminish the lesioned tissue area by contraction and fibroplasia, establishing a viable epithelial barrier to activate keratinocytes. This stage is responsible for the closure of the lesion itself, which includes angiogenesis, fibroplasia, and reepithelialization. These processes begin in the microenvironment of the lesion within the first 48 hours and can unfold up to the $14^{\text {th }}$ day after the onset of the lesion. ${ }^{14}$

Vascular remodeling prompts blood flow changes. Angiogenesis is a coordinated process, involving endothelial cellular proliferation, rupture and rearrangement of the basal membrane, migration and association in tubular structures, and the recruitment of perivascular cells. For some time, angiogenesis has been described as essential for diverse physiological and pathological conditions, such as embryogenesis, tumor growth, and metastasis. ${ }^{16}$

The subsequent development of the blood vessels, according to Gonçalves et al., involves the production of collateral veins through two mechanisms: germination and cell division. ${ }^{17}$ The resulting vascular plexus is remodeled to be differentiated in large and small blood vessels. The endothelium is then filled with both accessory and smooth muscle cells. The newly formed microvasulature makes it possible to transport fluid, oxygen, nutrients, and immune-competent cells to the stroma. ${ }^{18}$

In addition to the active participation of endothelial and lymphocyte cells in this biological process, pericytes constitute a cell group stemming from the mesenchymal strain of smooth muscle cells, described many decades ago. ${ }^{19}$ The aforementioned cells appear as solitary entities, sharing the basal membrane of blood vessels and endothelial cells (Figure 3). ${ }^{20}$ The pericytes are lightly-colored connective tissue cells containing long and thin cytoplasmatic processes in a position immediately outside of the endothelium of the blood capillaries and small venules into which the capillaries empty themselves. According to Ribatti et al., Charles Rouget, in 1873, was the first to describe such non-pigmented cells that presented contractible elements. ${ }^{21}$ However, these authors were unable to stain them. By contrast, Mayer, in 1902, using methylene blue stain, was able to view these cells, which were defined as pericytes by Zimmermann in 1923, due to their position on and around the blood vessels, with their processes wrapped around the basal surface of the endothelium.

Through long cytoplasmatic extensions that stretch and surround the endothelial tube, the pericyte makes focal contact with the endothelium through specialized junctures. ${ }^{22}$ Additionally, such a cell influences the stability of the blood vessel through the deposition of the matrix and/or the release and activation of signs that promote the differentiation or compliance of the endothelial cells. ${ }^{23,24}$

Pericytes are mural cells of micro-blood vessels involved in the basal membrane, which run continuously along the endothelial basal membrane. Some pericytes are most likely mesenchymal or progenitor cell strains that form adipocytes, cartilage, bone, and muscle. ${ }^{22}$ There is substantive evidence that the pericytes retain a mesenchymal potentiality during adulthood that is enough to create not only fibroblasts, but also smooth muscle cells. ${ }^{25}$ These cell elements can present pluripotent cell characteristics, which constitute an important "source of cell reserve." Though the plasticity of pericytes has yet to be fully studied, Farrington-Rock et al. reported its potential for differentiation into osteoblastos, chondrocytes, fibroblasts, leiomyocytes, and adipocytes. ${ }^{26}$ This property seems to be quite pertinent to tissue repair, given that these cells can offer an overall contribution to the restocking of scar tissue.

Granulation tissue begins to be formed approximately four days after the lesion. Its name is derived from the granular appearance of the recently-formed tissue, conferring this characteristic to the new stroma. According to Calin et al., the granulation tissue is formed through the following mechanisms: an increase in fibroblastic proliferation; collagenous and elastic biosynthesis, which creates a three-dimensional extracellular network of connective tissue; and the production of chemotactic factors and IFN-beta by fibroblasts. ${ }^{27}$ Fibroblasts and endothelial cells express integrin receptors and, through these, invade the coagulation found in the lesion area. ${ }^{28}$

For the tissue repair process to be understood, one must mention some particularities of the immune system, such as the participation of B lymphocytes and, more specifically, the multifunctionality of $\mathrm{T}$ lymphocytes. Morphologically, T lymphocytes are subdivided into functional populations: CD4 (auxiliary T lymphocytes) and CD8 (suppressor/cytotoxic T lymphocytes). The T CD4

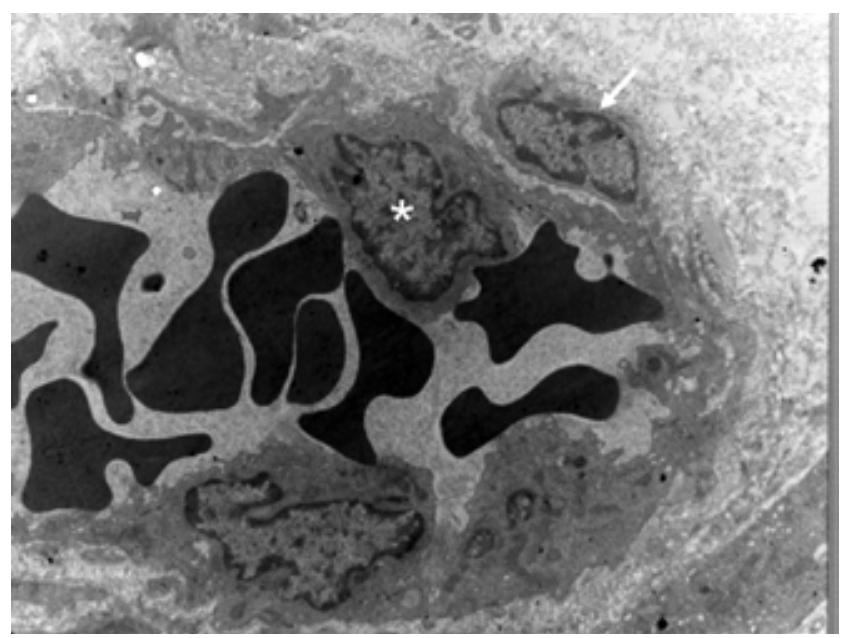

FIGURE 3: Electromicrography that illustrates the pericyte (arrow) in close contact with the endothelial cell (asterisk), sharing the basal membrane of this cell, which makes up the blood vessel wall (Scanning Electron Microscopy - 7,000X) 
cells are characterized based on their profiles of cytokine production, such as the subpopulation of Th1; producers of Il-2 and IFN gamma; Th2, which produces IL-4, IL-5, and IL-10; and Th17, which is characterized by the production of IL-17. ${ }^{2}$

When a tissue lesion occurs, the repair process is modulated by the cell activity of the inflammatory response of the cells on the borders of the lesion (keratinocytes), as well as by the variety of cytokines and growth factors that influence migration, proliferation, and local cell differentiation. ${ }^{29}$

Medrado et al. ${ }^{25}$ commented that fibroplasia begins with the formation of granulation tissue, characterized by the proliferation of fibroblasts, the main agents responsible for the deposition of the new matrix (Figure 4). The main component of a mature connective tissue scar is collagen. Fibroblasts, producers of collagen, are recruited from the dermis of the border of the wound to synthesize this protein. The formation of an intact basal membrane, between the epidermis and dermis, is essential for the reestablishment of its integrity and function. During this initial stage of repair, the type III collagen is predominant, synthesized by fibroblasts in the granulation tissue. ${ }^{30}$

Medrado et al. ${ }^{25}$ observed that the wound's contraction process begins at this stage, performed by the fibroblasts, which are rich in the alpha smooth muscle actin, known as myofibroblasts. Such cells, accumulated on the wounds' borders, execute contractive activities and contract the lesion's borders toward the center. ${ }^{27}$

Angiogenesis occurs in the extracellular matrix of the wound bed with the migration and mitogenic stimulation of the endothelial cells. ${ }^{15}$ Such neovascularization accompanies the fibroblastic stage mentioned above. The good irrigation of the borders of the wound is essential for wound healing, as this allows for an adequate supply of nutrients and oxygen, as well as of immune-competent cells, to the stroma (Figure 5). ${ }^{31,32}$

Parallel to all of the aforementioned events, the epithelial coating cells, through the action of specific cytokines, proliferate and migrate from the borders of the wound in an attempt to close it, which is called reepithelialization. The reepithelialization of a wound by keratinocytes is performed by the combination of the proliferative stage with the migration of cells near the lesion. ${ }^{14}$ The migration of keratinocytes occurs in the direction of the remaining skin of the lesion to its extremities.

Epidermal cells of hair follicles quickly remove the coagulation and damaged stroma. $\mathrm{Li}$ et al. ${ }^{14}$ reported that the epidermal germ cells of the hair follicle, which create the hair bulb, serve as a reservoir for keratinocytes in the healing process. Approximately ten hours after the onset of the lesion, there is a development and stretching of the pseudopod projections of the keratinocytes, a loss of the extracellular matrix-cell and cell-cell contacts, a retraction of the tonofilaments, and the formation of actin filaments in the extremities of its cytoplasms. When the migration ceases, possibly due to a result of the inhibition caused by contact, the keratinocytes are reconnected to the substrate and reconstruct the basal membrane. There is then the culmination of its differentiation process to generate the newly stratified epidermis (Figure 6). ${ }^{14}$

\section{REMODELING STAGE}

The third phase of healing consists of remodeling, which begins two to three weeks after the onset of the lesion and can last for one year or more. The core aim of the remodeling stage is to achieve the maximum tensile strength through reorganization, degradation, and resynthesis of the extracellular matrix. In this final stage of the lesion's healing, an attempt to recover the normal tissue structure occurs, and the granulation tissue is gradually remodeled, forming scar tissue that is less cellular and vascular ${ }^{3}$ and that exhibits a progressive increase in its concentration of collagen fibers (Figure 7).

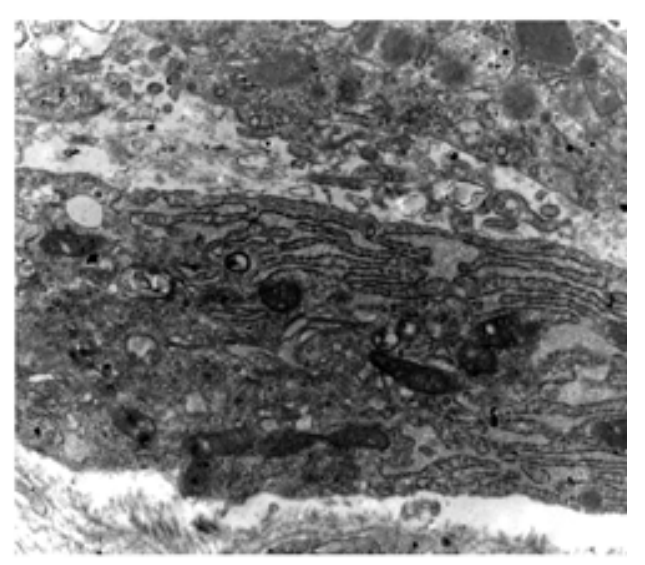

Figure 4:

Electromicrography presenting the part of the cytoplasm of a fibroblast that exhibits the hyperplasia of the endoplasmatic reticulum and mitochondria, illustrating an intense synthesis activity (Scanning Electron Microscopy $-12,000 X)$.

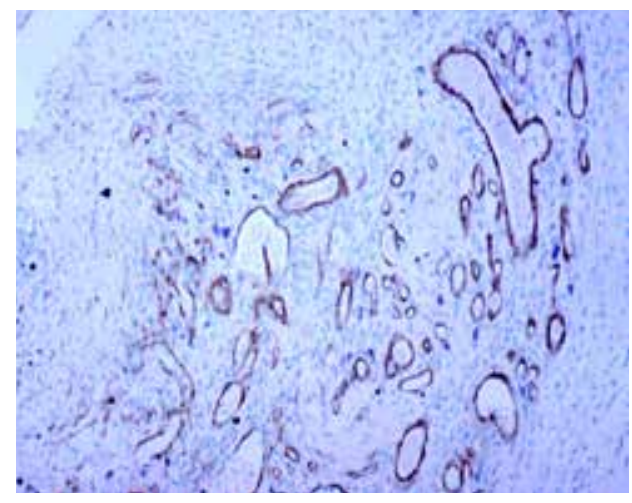

Figure 5:

Neoangiogenesis demonstrated by an immunomarker with an anti-alpha smooth muscle actin antibody in rat skin, three days after inducing the standard skin wound (Immuno-histochemical - 100X).

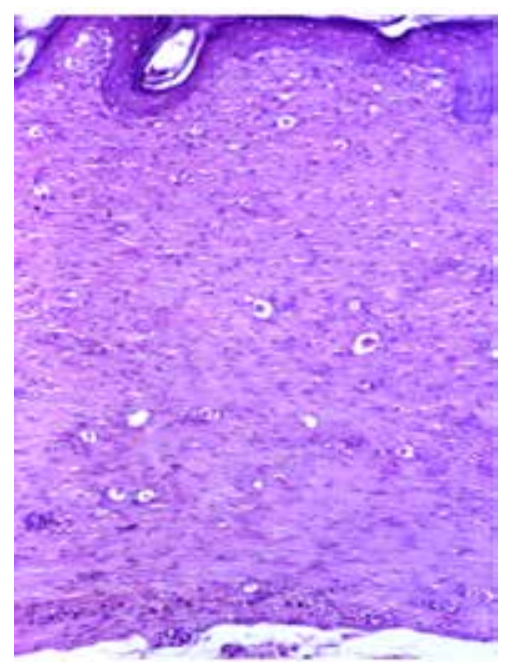

Figure 6:

Fibroplasia area demonstrating the absence of skin annexes in the extracellular matrix and complete reepithelialization of the epidermis (hematoxylin-eosin - 100X) 
This stage is marked by the maturing of the elements with deep changes in the extracellular matrix and the resolution of the initial inflammation. As soon as the surface of the lesion is covered by a monolayer of keratinocytes, its epidermal migration ceases and a new stratified epidermis with a subjacent basal lamina is reestablished from the borders of the wound to its inner portion. ${ }^{5}$ At this stage, there is a deposition of the matrix and subsequent change in its composition. ${ }^{14}$ With the closure of the wound, type III collagen undergoes degradation, and synthesis of type I collagen increases. Throughout the remodeling, there is a reduction in the hyaluronic and fibronectic acid, which are degraded by cells and plasmatic metalloproteinase, and the growing type I collagen expression mentioned above is concomitantly processed. ${ }^{17}$

Many authors, such as Sampaio \& Riviti, have confirmed that, in this final stage, the collagen fibers become thicker and are placed in parallel, resulting in an enhanced tensile strength for the tissue. ${ }^{33}$ The resolution stage is essential for the restoration of functionality and the "normal" appearance of the lesioned tissue. ${ }^{1}$ This results from the low production of chemokines by anti-inflammatory cytokines, such as IL-10 or TGF- $\beta 1$. The regulation of the collagen synthesis is controlled by a wide range of growth factors, such as TGF- $\beta 1$ and FGF, which cause a strong effect upon the genic expression of this protein.

During the maturation and remodeling processes, the majority of blood vessels, fibroblasts, and inflammatory cells disappear from the wound area due to emigration processes, apoptosis, or other unknown mechanisms of cell death. This fact leads to the formation of a scar with a reduced number of cells. At a later stage, the fibroblasts of the granulation tissue change their phenotype and begin to temporarily express the smooth muscle actin, which have received the specific name of myofibroblasts. ${ }^{6,27}$

Myofibroblasts, according to Calin et al..$^{27}$, acquire some contraction properties from smooth muscle cells, moving closer to the

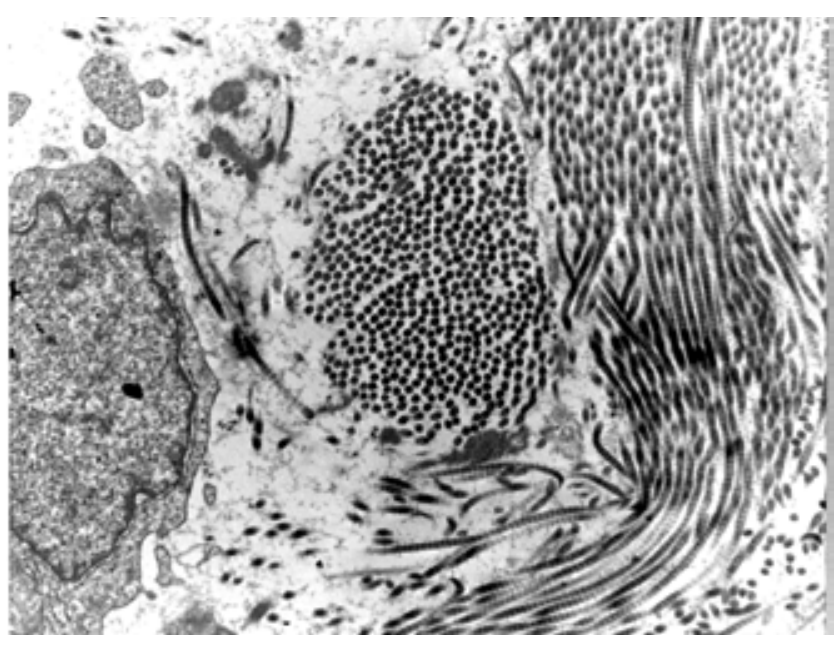

FiguRE 7: Electromicrography showing collagenous beams in different directions in the extracellular matrix, indicating the beginning of the process of fibroplasia, beginning on the seventh day after the onset of a skin wound, in an experimental model (Scanning Electron Microscopy - 12,000X) borders of the wound and becoming responsible for its contraction. In this manner, the referent cells present well-developed bands of contractible microfilaments composed of actin. These remain joined through communication junctures, and their cytoplasmatic filaments of actin are connected by integrin receptors to the fibronectin fibrils and to collagen I and III of the extracellular matrix. ${ }^{1,14}$ It is important to note that the myofibroblasts are the main producers of the extracellular matrix in processes of fibrosis. ${ }^{31}$

According to Midwood et al..$^{34}$ and Badylak ${ }^{35}$, the extracellular matrix is not a static element and is capable of playing a relevant role in this stage of tissue repair through the interaction between its structural components and the different cell types present in the tissue. Such structural components, represented by proteins such as collagen, fibronectin, fibrin, among others, provide signs and unleash specific cell activities in the wound area. The fibronectin, for example, generates a framework that makes the adhesion and cell migration feasible. Another adhesive glycoprotein, vitronectin, can contribute to the contraction of the tissue mediated by the collagen produced by the fibroblasts. Due to the existence of these processes, the local control of the cell/matrix interactions have been the target of promising therapeutic approaches.

In all of the processes cited above, it is important to emphasize that exogenous and endogenous factors can modulate such events and influence the healing process. More specifically, systemic disorders, such as diabetes, immunosuppression, venous stasis, as well as those resulting from external agents, such as the use of corticotherapy and smoking, can hinder the early closure of the wound. In addition to these complicating factors is the appearance of hypertrophic scars and keloids. ${ }^{36}$

\section{EPITHELIAL-MESENCHYMAL INTERACTION IN} HEALING

The epithelial cells undergo an epithelial-mesenchymal transition (EMT) and migrate to the organs to differentiate themselves in their mesenchymal components, including fibroblasts, smooth muscle cells of blood vessels, and, even more likely, pericytes. ${ }^{22}$

The skin, as well as the intestines, liver, lungs, and glandular tissues, contains epithelial and mesenchymal cells. The epithelial cells firmly adhere one to another, forming layers in which the basoapical polarity can be observed. The mesenchymal cells are non-polarized and are capable of movement, such as individual cells due to the loss of intercellular connections. ${ }^{37}$

The biological process that occurs in the epithelial-mesenchymal transition makes it possible for a polarized epithelial cell to undergo molecular changes, acquiring a mesenchymal phenotype, with migratory capacity through the extracellular matrix, resistance to apoptosis, and increase in the production of the components of the matrix. ${ }^{38}$

Though first studied in a tumor context, the expression of normal promotor and/or inhibitor regulatory genes from cell growth, which are expressed in the cells present in the extracellular matrix, occurs in the healing process. Liu et al. described that the epithelial-mesenchymal transition can be regulated by microRNAs, as seen in miR-221, as well as by other oncogenes. Tome-Garcia et al. reported that the overexpression of the ras gene and the ERBB2 
resulted in an increase in cell mobility in the extracellular matrix and in the metastatic potential of prostate cancer. Though these alterations have been described in the tumor microenvironment, such results can be observed in the healing process as well. . $^{39,40}$

Three types of epithelial-mesenchymal transition are known. Type I occurs when the tissues are constructed during embryogenesis, as can be seen in the dermal fibroblasts of the connective tissue, which provides determining signs for positioning, types of skin, and other skin appendages that will differentiate themselves into the overarching epidermis. ${ }^{5}$ The epithelial-mesenchymal transition also occurs in adult tissues in reaction to the remodeling and to fibrosis (type II). ${ }^{38}$ The metastatic process (type III) includes carcinoma cells that undergo phenotypical conversion and acquire mobility, using the epithelial-mesenchymal transition program, which normally serves to generate adult fibroblasts. ${ }^{41}$

Type II epithelial-mesenchymal transition is associated with tissue healing, regeneration, and fibrosis. Such an event, linked to tissue repair, creates fibroblasts and other cells related to the objective of reconstructing tissues resulting from traumas and inflammation. This type of epithelial-mesenchymal transition, associated with inflammation, ceases as soon as it has been alleviated. ${ }^{41}$

Through molecular analyses, it was possible to identify the majority of morphogenic factors, which include a network of signs between the epithelium and the mesenchyme, including Bmp, Wnt (wingless), Notch/Delta, and Hedgehog. ${ }^{42}$ The mechanisms of Wnt and Notch signaling are critically involved in the defining of the terminal differentiation of the cells that participate in skin tissue repair. Shi et al. ${ }^{43}$ conducted an experimental study in which the participation of these signaling pathways during healing was evaluated. The authors observed that the increment in the activity of such signaling pathways promoted the closure of skin wounds in the studied specimens, and their inhibition or activation can affect the proliferation of stem cells, as well as the differentiation and migration of keratinocytes and the regeneration of hair follicles.

In addition, according to Sicklick et al. ${ }^{44}$ there are hypotheses that microfibroblasts can produce the Hedgehog ligand, a transmembrane protein that also controls tissue construction and remodeling, regulating the viability and migratory activity of various responsive cell types to the referent ligand.

\section{HEDGEHOG SIGNALING PATHWAY}

Hedgehog $(\mathrm{Hh})$ is a family of secreted signaling molecules that are involved in many processes, including the role as key agents in the standardization of numerous tissues types. ${ }^{45}$ This family comprehends a cascade of proteins that regulate diverse biological processes, such as embryological development, homeostasis, tumorigenesis, and tissue repair. Considering that the hedgehog ligand can regulate angiogenesis, its signaling can also influence tissue remodeling.

The hedgehog gene was first identified in genetic works about the segmentation of the body in Drosophila melanogaster, the fruit fly. The German researchers, Nüsslein and Wieschaus, in 1980, studying the genetic control of the embryos of Drosophila melanogaster, identified that the loss of a gene caused projections within these. ${ }^{46}$ Such a mutating phenotype acquires an oval form, with dis- organized denticles, resembling a hedgehog.

The equivalents of th have been identified in many invertebrates and vertebrates and have been preserved, playing similar vital roles in the control of tissue standardization, differentiation, and cell proliferation in the embryological development and control of germ cell behavior and homeostasis in adults. ${ }^{47}$ This pathway is of utmost importance in development, especially in the formation of the limbs and neural tubes. ${ }^{48}$

Many genes have been identified to codify cytoplasmatic components of the transduction machinery of Hh signaling. Three equivalents, identified in vertebrates, of the Hh gene were designated by the following prefixes: Sonic (Shh), Indian (Ihh), and Desert (Dhh). ${ }^{49,50}$

The Hh pathway can be initiated, according to Omeneti et al., by autocrines, paracrines, and endhocrines. ${ }^{51}$ The Hh ligands are synthesized and undergo autocatalysis to generate an N-terminal fragment, which is modified by the addition of cholesterol and palmitate, before being released into the extracellular space. ${ }^{52}$

The activation of the hedgehog signaling pathway is performed by the connection of one of the family members in the 12pass receptor in the membrane, called Patches (Ptch). This work was associated with a 7-pass co-receptor in the membrane, called Smoothened (Smo). ${ }^{53}$ In the absence of the hedgehog ligand, the Ptch receptor inhibits the Smo co-receptor, which remains in vesicles at the base of the primary cilium and, therefore, far from the transcription factors of Gli-1, 2, and 3, which are abundant on the surface of this organelle..$^{52}$ This forces the Gli-3 to be transported through microtubes to the proteasome, where it is partially degraded, forming a Gli-3 repressor fragment that enters the nucleus and restricts the transcription of the target genes involved in differentiation, survival, and cell proliferation.

The activation of Smo, through inhibition mediated by Ptch, inhibits the proteolytic processing of Gli-2 and Gli-3, in turn releasing the product for transcriptional activation. ${ }^{43}$ By contrast, when $\mathrm{Hh}$ is connected to Ptch, the internalization of this receptor occurs, releasing the Smo co-receptor, which migrates to the top of the primary cilium, where it activates the Gli family of transcription factors. This includes the Gli-1, 2, and 3, which migrate to the nucleus, activating the transcription of this pathway's target genes. ${ }^{47}$

The disorders of development in the hedgehog signaling may well be due to inactivation or overactivation. Teglund \& Tofgard $^{48}$ (2010) described that the inappropriate activation of hedgehog signaling contributes to various types of cancer and syndromes. Luo et al. ${ }^{54}$ showed that the activity of Sonic hedgehog (Shh) is necessary for normal healing and that, in mice with diabetes, such a pathway is blocked, given that the exogenous application of Shh accelerates the healing process by increasing the nitrous oxide (NO) function.

Cutaneous wound healing reproduces the majority of biological phenomena that characterize this process found in different tissues and constitutes an excellent model of study to evaluate the multiple stages of tissue repair. These stages are finely regulated by signaling molecules produced by a wide range of cells present in the extracellular matrix. New studies are warranted in an attempt to detail the possible epithelial-mesenchymal interactions that contribute to the transformations of tissues affected by lesions.] 


\section{REFERENCES}

1. Shaw TJ, Martin P. Wound repair at a glance. J Cell Sci. 2009;122:3209-13.

2. Eming SA, Krieg T, Davidson JM. Inflammation in wound repair: molecular and cellular mechanisms. J Invest Dermatol. 2007;127:514-25.

3. Cotran, RS, Abbas AK, Fausto N, Robbins SL, Kumar V. Robbins \& Cotran: Patologia - Bases Patológicas das Doenças. 7. ed. Rio de Janeiro: Elsevier, 2005. 1592 p.

4. Nayak BS, Sandiford S, Maxwell A. Evaluation of wound healing of ethanolic extract of Morinda cetrifolia L leaf. Evid Based Complement Alternat Med. 2009;6:351-6.

5. Martin P. Wound Healing - Aiming for a perfect skin regeneration. Science. 1997:276:75-81.

6. Medrado AR, Pugliese LS, Reis SR, Andrade ZA. Influence of low level laser therapy on wound healing and its biological action upon myofibroblasts. Lasers Surg Med. 2003;32:239-44.

7. Buckley $\mathrm{C}$. Why does chronic inflammation persist: na unexpected role of fibroblastos. Immunol Lett. 2011;138:12-4.

8. Gurtner GC, Werner S, Barrandon Y, Longaker MT. Wound Repair and Regeneration. Nature. $2008 ; 453: 314-21$

9. Nunes PS, Albuquerque RL Jr, Cavalcante DR, Dantas MD, Cardoso JC, Bezerra MS, et al. Collagen-based films containing liposomes loaded using acid as dressing for dermal burn healing J Biomed Biotechnol. 2011;2011:761593.

10. Thuraisingam T, Xu YZ, Eadie K, Heravi M, Guiot MC, Greemberg R, et al. MAPKAPK-2 signaling is critical for cutaneous wound healing. J Invest Dermatol. 2010;130:278-86.

11. Rodero MP, Khosrotehrani K. Skin wound healing modulation by macrophages. Int J Clin Exp Pathol. 2010:3:643-53.

12. Singer AJ, Clark RA. Cutaneous Wound Healing. N Engl J Med. 1999;341:738-46.

13. Tidball JG. Inflammation process in muscle injury and repair. Am J Physiol Regul Integr Comp Physiol. 2005;288:R345-53.

14. Li J, Chen J, Kirsner R. Pathophisiology of acute wound healing. Clin Dermatol. 2007;25:9-18.

15. Mendonça RJ, Coutinho-Netto J. Aspectos celulares da cicatrização. An Bras Dermatol 2009;84:257-262.

16. Rosen BP. Biocemistry of arsenic detoxification. FEBS Lett. 2002;529:86-92.

17. Gonçalves RV, Souza NTA, Silva PH, Barbosa FS, Neves CA. Influência do laser de arseneto de gálio-alumínio em feridas cutâneas de ratos. Fisoter Mov. 2010:23:381-8

18. Carmeliet P. Angiogenesis in health and disease Nat Med. 2003;9:653-60.

19. Crocker DJ, Murad TM, Geer JC. Role of the pericyte in wound healing an ultrastructural study. Exp Mol Pathol. 1970;13:51-65.

20. Alon $\mathrm{R}$, Nourshargh $\mathrm{S}$. Learning in motion: pericytes instruct migrating innate leukocytes. Nat Immunol. 2013;14:14-5

21. Ribatti D, Nico B, Crivellato E. The role of pericytes in Angiogenesis. Int J Dev Biol. 2011:55:261-8.

22. Armulik A, Genové G, Betsholtz C. Pericytes: Developmental, Physiological and Pathological Perspectives, Problems and Promises. Dev Cell. 2011;21:193-215.

23. Xian X, Håkansson J, Ståhlberg A, Lindblom P, Betsholtz C, Gerhardt H, et al. Pericytes limit tumor cell metastasis. J Clin Invest. 2006;116:642-51.

24. Takakura N. Role of hematopoietic lineage cells as accessory components in blood vessel formation. Cancer Sci. 2006:97:568-74.

25. Medrado A, Costa T, Prado T, Reis S, Andrade Z. Phenotype characterization of pericytes during tissue repair following low-level laser therapy. Photodermatol Photoimmunol Photomed. 2010;26:192-7.

26. Farrington-Rock C, Crofts NJ, Doherty MJ, Ashton BA, Griffin-Jones C, Canfield $A E$. Chondrogenic and adipogenic potential of microvascular pericytes. Circulation. 2004;110:2226-32.

27. Calin MA, Coman T, Calin MR. The effect of low level laser therapy on surgical wound healing. Rom Rep in Phys 2010;62:617-27.

28. Tonnesen MG, Feng X, Clark RA. Angiogenesis in wound healing. J Investig Dermatol Symp Proc. 2000;5:40-6.

29. Mason DE, Mitchell KE, Li Y, Finley MR, Freeman LC. Molecular basis of voltagedependent potassium currents in porcine granulosa cells. Mol Pharmacol. 2002;61:201-13

30. Isaac C, Ladeira PRS, Rego FMP, Aldunate JCB, Ferreira MC. Processo de cura das feridas: cicatrização fisiológica. Rev Med. 2010;89:125-31.

31. Tazima MFGS, Vicente YAMV, Moriya T. Biologia da Ferida e Cicatrização. Simpósio: Fundamentos em Clínica Cirúrgica. Medicina. 2008;4:259-64.

32. Ruiter DJ, Schlingemann RO, Westphal JR, Denijn M, Rietveld FJ, De Waal RM. Angiogenesis in wound healing and tumor metastasis. Behring Inst Mitt. 1993;92:258-72.
33. Sampaio SA, Rivitti E. Dermatologia. 2. ed. São Paulo: Artes Médicas; 2001

34. Midwood KS, Williams LV, Schwarzbauer JE. Tissue repair and the dynamics of the extracellular matrix. Int J Biochem Cell Biol. 2004;36:1031-7.

35. Badylak SF. The extracellular matrix as a scaffold for tissue reconstruction. Semin Cell Dev Biol. 2002;13:377-83.

36. Fonseca MA, Almeida RR, Reis SRA, Medrado ARAP. Repercussão de doenças sistêmicas no reparo tecidual. Rev Bahian Odont. 2012;3:63-75.

37. Friedman SL. Mechanisms of hepatic fibrogenesis Gastroenterology. 2008;134:1655-69.

38. Choi SS, Diehl AM. Epithelial-to-Mesenchymal transitions in liver. Hepatology. 2009;50:2007-13

39. Liu J, Cao J, Zhao X .miR-221 facilitates the TGFbeta1-induced epithelialmesenchymal transition in human bladder cancer cells by targeting STMN1. BMC Urol. 2015;15:36.

40. Tome-Garcia J, Li D, Ghazaryan S, Shu L, Wu L. ERBB2 increases metastatic potentials specifically in androgen-insensitive prostate cancer cells. PLoS One. 2014:9:e99525.

41. Zeisberg M, Neilson EG. Biomarkers of epithelial-mesenchymal transitions. J Clin Invest. 2009:119:1429-37.

42. DeRouen MC, Oro AE. The primary cillium: a small yet mighty organelle. J Invest Dermatol. 2009;129:264-5.

43. Shi Y, Shu B, Yang R, Xu Y, Xing B, Liu J, et al. Wnt and Notch signaling pathway involved in wound healing by targeting separately c-Myc and Hes1. Stem Cell Res Ther. 2015;6:120.

44. Sicklick JK, Li YX, Jayaraman A, Kannangai R, Qi Y, Vivekanandan P, et al. Dysregulation of the hedgehog pathway in human hepatocarcinogenesis Carcinogenesis. 2006;27:748-57.

45. Nybakken K, Perrimon N. Hedgehog signal transduction: recent findings. Curr Opin Genet Dev. 2002;12:503-11.

46. Nüsslein-Volhard $\mathrm{C}$, Wieschaus $\mathrm{E}$. Mutations affecting segment number and polarity in Drosophila. Nature. 1980;287:795-801.

47. King PJ, Guasti L, Laufer E. Hedgehog signalling in endocrine development and disease. J Endocrinol. 2008;198:439-50.

48. Teglund S, Toftgård R. Hedgehog beyond medulloblastoma and basal cell carcinoma Biochim Biophys Acta. 2010;1805:181-208.

49. Echelard Y, Epstein DJ, St-Jacques B, Shen L, Mohler J, McMahon JA, et al. Sonic hedgehog, a member of a family of putative signaling molecules, is implicated in the regulation of CNS polarity. Cell. 1993;75:1417-30.

50. Ingham PW, McMahon AP. Hedgehog signaling in animal development: paradigms and principles. Genes Dev. 2001;15:3059-87.

51. Omenetti A, Choi S, Michelotti G, Diehl AM. Hedgehog signaling in the liver. Hepatol. 2011;54:366-73.

52. Pepinsky RB, Zeng C, Wen D, Rayhorn P, Baker DP, Williams KP, et al. Identification of a palmitic acid-modified form of human Sonic hedgehog. J Biol Chem. 1998;273:14037-45.

53. Cohen Jr MM. Hedgehog signaling update. Am J Med Genet A. 2010;152A:1875914.

54. Luo JD, Hu TP, Wang L, Chen MS, Liu SM, Chen AF. Sonic hedgehog improves wound healing via enhancing cutaneous nitric oxide function in diabetes. Am J Physiol Endocrinol Metab. 2009;297:E525-31.

\author{
MAILING ADDRESS: \\ Ana Cristina de Oliveira Gonzalez \\ R. Waldemar Falcão, 121 \\ Candeal \\ 40296-710 Salvador, BA \\ E-mail: tilafortuna@gmail.com
}

How to cite this article: Gonzalez AC, Costa TG, Andrade ZA, Medrado ARAP. Wound healing - A literature review. An Bras Dermatol. 2016;91(5):614-20. 